\title{
University-Industry Relations and Industrial Innovation: Evidence from Brazil
}

\author{
Andrei Mikhailov ${ }^{1^{*}}$, Daniel Puffal ${ }^{1}$, Mateus Santini ${ }^{1}$
}

\begin{abstract}
University-industry relations are an important factor for industrial innovation. However, the results of these relationships for the firms remain largely unmeasured. Moreover, the contribution of different types of interactions to firm innovativeness is kn own ma inly in theoretical terms. Departing from a secondary data of Brazilian university-industry interaction survey, also known as "BR survey", this study employs crispset qualitative comparative analysis (csQCA) to identify how five types of University-industry interactions - training-oriented, service-oriented, diffusion-oriented, d evelopment-oriented, a nd r esearch-oriented - combine to p roduce high i nnovation o utput. The re sults sh ow th at th e mo st complex interactions - development-oriented and research-oriented - are the only types of interactions that alone lead the firm to high innovativeness. In contrast, less complex interactions alone are not enough to make the firm innovate beyond the "new-to-the-firm" level and need to be complemented by more complex interaction.
\end{abstract}

Keywords: innovation; university-industry interaction; crisp-set QCA; manufacturing firms; Brazil.

Submitted: July $15^{\text {th }}, 2020 /$ Approved: October $22^{\text {nd }}, 2020$

\section{Introduction}

Innovation is not a development of one individual firm, but an interactive process which interconnects the market view of companies to the scientific development of universities (West et al., 2014). For that reason, universities play a crucial role in society as producers of stateof-art scientific knowledge (D'este and Patel, 2007).

The innovative economies use cooperation with universities as a source of state-of-art knowledge and technology, and many of the world's most economically advanced regions possess top-tier academic and research institutions (Etzkowitz et al., 2019; Henton \& Held, 2013). In contrast, universities in emerging economies are more likely to engage in testing, adapting, and diffusion of foreign technology to local demands, supporting the national industry (Fu \& Li, 2016). However, as shown by some recent studies (i.e. Schaeffer; Dullius; Rodrigues; Zawislak, 2017), in Brazil the most common University-Industry (UI) interactions are development-oriented, therefore, many firms do seek university not just to improve existing products or processes, but to achieve higher level innovativeness.

There are some empirical studies that analyzed factors that influence the innovativeness of the firms that interacted with universities (Bishop, D’Este, Neely, 2011; Kobarg, Stumpf-Wollersheim, Welpe, 2018; $\mathrm{Li}, \mathrm{Li} \& \mathrm{Wu}, 2019)$. However, in general, the number of studies that checked the relations between firms' innovation performance and UI interaction per se is surprisingly low. Some studies, for instance, only checked whether the presence of cooperation, regardless of its aim, affects innovative performance (Arant, Fornahl, Grashof, Hesse, Sollner, 2019). Also, studies tend to measure firm innovativeness in the number of patents (i. e. Arant et al. 2019; Baba, Shichijo, Sedita, 2009). However, patent applications do not necessarily translate into the creation of new products or processes and vice versa, particularly in low-tech sectors (Reichert, Zawislak, Arundel, 2016; Smith, 2005).
While measuring the impact of UI interaction on innovativeness, the previous studies did not ask the companies whether they consider UI interaction as an important source for firms' innovation activities (Baba et al., 2009). Moreover, the knowledge on which type of UI interaction or configuration of UI interaction does lead to high innovative performance remains unknown, at least from an empirical point of view.

In this context, we propose the following research question: which are, whether exist, the best configurations of UI interactions that firms should engage to achieve high innovativeness? The method used to conduct the study had two steps. First, a crisp-set qualitativecomparative method (csQCA) was applied to a sample of manufacturing firms to determine the required types of UI relations that will lead the firm to high innovativeness. Second, the cases covered by csQCA solutions were analyzed.

The results showed that research-oriented interactions (RE) and development-oriented interactions (DE) are the only interactions with universities that alone can allow the firm to achieve high innovativeness. Moreover, these results apply to firms from different sectors, different sizes, and different R\&D intensity. In contrast, the diffusionoriented interactions (DI), which is less complex than science-oriented and development-oriented (Schaeffer et al., 2017) showed no contribution to the firm's high innovativeness.

We highlight that among firms that interact with universities those that engage in more complex relations tend to achieve a higher level of innovativeness than those that do not. These results suggest that it is important for the firm to engage in more complex, long-term UI interactions to achieve high innovativeness. In turn, this brings important theoretical, empirical and policy implications.

The paper is structured as follows. After introduction, universityindustry interaction literature is presented. Section three includes

(1) Unisinos Business School, Porto Alegre, Brazil

*Corresponding author: andreimikh@gmail.com

ISSN: 0718-2724. (http://jotmi.org)

Journal of Technology Management \& Innovation ( ) Universidad Alberto Hurtado, Facultad de Economía y Negocios. 
the method description. The results and discussion are presented in section four. The conclusion is made in section five. Finally, references are listed.

\section{University-industry interaction}

In recent decades, it has been observed that a greater number of universities, in the most diverse countries, have been increasingly involved in innovation and industrial development, the so-called third mission (Wang, Hu, Li, Li, \& Li, 2015). According to Etzkowitz (1998), universities were established with the primary objective of teaching (first mission). In the 19th century, research was integrated as one of the main activities of universities (second mission). After the 1980s, another turning point in the evolution of studies on the roles of universities in society was represented by the emergence of the third mission. Since then, the academy is no longer seen only as a producer and disseminator of knowledge, but also has the function of creating relationships, which can be equally important (Andersson \& Berggren, 2016). Thus, researching the context of universities has great relevance as they are increasingly playing a central role in advancing sustainability on a local, regional and national scale through intersectoral collaborations (Trencher, Bai, Evans, McCormick, \& Yarim, 2014)

The interaction between scientific production and technological production plays an important role in innovation systems (Mazzoleni \& Nelson, 2007). It is possible to identify the existence of positive feedback circuits between these two dimensions, where there are flows of information and knowledge in both directions (Cohen, Nelson \& Walsh, 2002). One of the important roles of universities for the development of countries is the advance on the frontier of knowledge with a view to its applicability in the productive sector. Universities are general sources of knowledge necessary for basic research activities (Nelson, 1990), as well as sources of specialized knowledge related to technologies applied in companies (Klevorick, Levin, Nelson, \& Winter, 1995), in addition to being responsible for the education and training of scientists and engineers able to solve problems related to companies' innovative process (Rosenberg \& Nelson, 1994).

Companies, on the other hand, are increasingly focused on cooperation with universities (Mascarenhas, Ferreira \& Marques, 2018), this being a solution adopted mainly by those that are intensive in R\&D (Lam, 2007). The emergence of this relationship between university-industry (UI) as the main actors in the development of the innovation system has cultivated the links between science and industry, generating various forms of collaboration (Yoon, 2015), promoting economic progress, innovation and competitiveness (Skute, Zalewska-Kurek, Hatak, \& de Weerd-Nederhof, 2019). This approximation between UI is developed in different ways and several researchers have placed emphasis on the ways in which relationships are established. Etzkowitz and Zhou (2018), cite technology parks and attribute to them an interactive model that generates entrepreneurial activity through various means, including incubator projects and academic programs. Clark (2005), on the other hand, emphasizes the accumulation of business groups within universities - these groups extend from disciplinary departments and interdisciplinary and transdisciplinary research centers at the base, to colleges and schools at intermediate levels, for the entire university. In these places, it is possible to find teachers and managers intertwined at all levels, involved in all issues.

The relationship of academics with industry is largely compatible with the continuous generation of scientific results (D'este \& Perkmann, 2011). According to Elia, Secundo \& Passiante (2017), the collaboration between science and technology is intense, usually with a focus within the university in a supporting role of the industry. This industry knowledge transfer is an important source of creation for all partners (Alexander, Martin, Manolchev \& Miller, 2018), however, the academy's ability to effectively transfer knowledge to the industry is essential for universities to fulfill their mission and entrepreneurial ambition (Miller, Alexander, Cunningham \& Albats, 2018). Within this context, relevant policies may be needed to facilitate collaboration in improving innovation efficiency at different stages (Shi, Wu, \& Fu, 2020). Recently, policymakers and industry strategists in developing countries have started to devote more attention to initiatives that promote collaboration between universities and industries. The main objective of these initiatives is to improve the capacities and efficiency of innovation systems, leveraging the role of universities as generators and disseminators of valuable knowledge (Fischer, Schaeffer, Vonortas \& Queiroz, 2018).

There are many types of UI relations. Among them we can highlight consultancy (D'Este \& Patel, 2007; Meyer-Krahmer \& Schmoch, 1998), contract research (D’Este \& Patel, 2007; Meyer-Krahmer \& Schmoch, 1998; Santoro, 2000), education of personnel (Meyer-Krahmer \& Schmoch, 1998), technology transfer (Santoro, 2000), formal agreements without clearly defined goals (Bonaccorsi \& Piccaluga, 1994), use of universities' facilities and informal meetings (Bishop et al., 2011; Puffal, Ruffoni, Schaeffer, 2012).

Recently, Schaeffer et al. (2017) compiled different typologies according to aspects and dimensions of UI relations previously identified by the academic scholars, which are: duration of the relationship, the direction of information flow, level of knowledge involved; the degree of formality, the complexity of interaction, the absorptive capacity of the actors.

Thus, Schaeffer et al. (2017) suggested that there are five types of UI cooperation: training-oriented, service-oriented, diffusion-oriented, development-oriented, and science-oriented. Table 1 shows the description of each relation type. 
Table 1. Typology of UI relationships according to Schaeffer et al. (2017)

\begin{tabular}{lll}
\hline Type of interaction & Level of complexity & Description \\
\hline Training-oriented & Low & $\begin{array}{l}\text { Consists of human resources training. Since this type of relationship does not necessarily imply } \\
\text { long-term interactions, there is no need for high absorptive capacity. The level of complexity of the } \\
\text { interaction is low. }\end{array}$ \\
\hline Service-oriented & $\begin{array}{l}\text { Comprehends services supplied by universities and industries, such as technical consulting acti- } \\
\text { vities and the utilization of facilities made available by the partner. Information flow is low. One } \\
\text { example of the services within the manufacturing sector is the use of laboratories for tests. }\end{array}$ \\
\hline Liffusion-oriented & $\begin{array}{l}\text { Consists of public technological knowledge and currently available solutions, require a low level of } \\
\text { knowledge and therefore low levels of absorptive capacity. An example of this type of relationship is } \\
\text { patent transfer. This relationship usually possesses a low level of complexity. }\end{array}$ \\
\hline Development-oriented & $\begin{array}{l}\text { Through this relationship the parties target joint technological development. In this type of interac- } \\
\text { tion, participants are active, even when results are used in the short run only. This type of relation- } \\
\text { ship attempts to bridge the knowledge gaps between industries and universities. }\end{array}$ \\
\hline High & $\begin{array}{l}\text { It represents the most complex relationship and requires the participants to be active in scienti- } \\
\text { fic and technological research. The relationship occurs in a long run and requires a high level of } \\
\text { absorptive capacity This type of interaction is therefore desirable in the U-I interaction context, } \\
\text { however, is often restricted to few sectors }\end{array}$
\end{tabular}

Note. Source: Schaeffer et al. (2017)

It's important to add that some previous studies showed that knowledge inflows from universities, that is, science-based flows, tend positively impact on firm innovativeness (Bishop et al., 2011; Murovec \& Prondan, 2009), including firms from emerging markets (Puffal \& Teixeira, 2014). Arza (2010) also argues that long-term interactions may impact more on firm innovation output than less complex, service, and consultancy-based interactions. However, there are also studies that showed that UI interaction per se does not have a significant influence on innovation (Eom \& Lee, 2010), at least in some cases (Baba et al., 2009). Moreover, in empirical terms, it is still not clear which type of UI relationships are the best in terms of allowing the firm to achieve high-level innovation output. Therefore, the present study aims to check which are, if exist, combinations of UI relationships that do lead to high-level innovation output.

Considering the Brazilian national context, we can observe the results of the national innovation survey - PINTEC. It indicates that Brazilian companies have shown certain stability in the rate of product and/ or process innovation. Since the beginning of the survey, in 1998, the average innovation incidence has been around 35\%. During the years 2009-2011, the incidence was $35.6 \%$, between 2012-2014, it was $36.4 \%$, and in the three years 2015-2017 the innovation incidence dropped to $33.6 \%$, it shows a decrease compared to the previous, which suggests a recent phase of a greater increase in the difficulties faced by companies to carry out innovation (IBGE, 2020). The database used in this article, called BR Survey, comes from a survey conducted with 325 companies that had interactions with universities. The data indicate that in this group of companies the incidence of innovation was $91.4 \%$. Despite the highly innovative performance of this group, it is not possible to say that there are a cause and effect relationship with the university-industry interaction. However, there is a positive correlation between the university-company interaction and the innovative performance of the companies, indicating that the interaction can be an important element for innovation when compared with the PINTEC data.

Several articles were produced from this database that analyzed issues as the motivation for the interactions, the funding influence, the types of relationships, among others. Pinho (2018) stands out that among many relevant results found from this database, the knowledge transfer channels, such as university publications and informal exchange information are more important than usual technology transfer mechanisms, like incubators, technology licensing and spin-offs, results also pointed out by Puffal and Teixeira (2014).

Pinho (2018), as well as Schaeffer et al. (2017), indicate that there is evidence to affirm that Brazilian companies value the contribution of universities to their innovative effort and that the relations between universities and companies, in Brazil, not only exist but are relatively intense. However, the relationship is not usually focused on innovations of greater scope, based on the forefront of scientific knowledge, which can be justified by the technological demand of companies.

\section{Method}

This paper draws on a secondary data retrieved from a national databank of UI relations survey conducted in 2008-2009 by the main Brazilian universities within a project called "University-industry cooperation in Brazil", also known as "BR Survey", and CNPQ Database 2004, a Brazilian census of universities research groups.

The UI relations survey was based on the Carnegie Mellon Survey on Industrial R\&D (Cohen et al., 2002) and the Yale Survey on Industrial R\&D (Klevorick et al., 1995). Currently, it is a largest innovation database on UI cooperation in Brazil. The UI relations survey database was constructed as follows: 
- Out of CNPQ Database 2004, only those groups that declared to have cooperated with private companies were selected. The procedures resulted in 2.151 research groups, which declared to have cooperated with 1.688 companies with different pay tax numbers.

- The 1.688 companies were contacted by phone call and to those that accepted to take part in a survey, it was sent an online questionnaire. In total, $19.3 \%$ of the companies accepted to take part in a survey, resulting in a final sample of 325 firms $^{1}$, including 196 manufacturing firms ${ }^{1}$.

As shown in Table 2, manufacturing companies that took part in the survey were firms of different sizes, $R \& D$ intensity rates, and from different economic sectors.

Table 2. Economic sector, size and R\&D intensity of manufacturing firms from BR survey

\begin{tabular}{|c|c|c|c|c|c|c|c|}
\hline \multicolumn{4}{|c|}{ Size } & \multicolumn{3}{|c|}{ R\&D investment (\% of revenue) } & \multirow[b]{2}{*}{ Total } \\
\hline Sector & Small & Medium & Large & $<1$ & 1 to 3 & $>3$ & \\
\hline Ceramic products & 4 & 2 & 3 & 0 & 7 & 2 & 9 \\
\hline Electrical equipment & 4 & 2 & 2 & 1 & 4 & 3 & 8 \\
\hline Food and beverage & 14 & 9 & 7 & 7 & 21 & 3 & 30 \\
\hline Furniture & 0 & 2 & 1 & 1 & 2 & 0 & 3 \\
\hline Medical equipment & 5 & 2 & 0 & 0 & 7 & 0 & 7 \\
\hline Metal products & 4 & 6 & 13 & 3 & 12 & 8 & 23 \\
\hline Mineral products & 2 & 0 & 2 & 2 & 2 & 0 & 4 \\
\hline Oil and fuel & 1 & 1 & 4 & 1 & 1 & 4 & 6 \\
\hline Optical equipment & 1 & 0 & 0 & 0 & 1 & 0 & 1 \\
\hline Pharmaceuticals & 11 & 9 & 6 & 4 & 14 & 8 & 26 \\
\hline Precision instruments & 2 & 2 & 0 & 0 & 2 & 2 & 4 \\
\hline Rubber and plastic & 1 & 5 & 2 & 3 & 3 & 2 & 8 \\
\hline
\end{tabular}

Note. Source: Compiled by the authors through BR Survey databank

Figure 1 shows the procedures for the final sample selection. In order to maximize the association between engagement in UI relations and innovation outcomes, out of 196 manufacturing firms with different taxpayer numbers, researchers selected those firms which consider university as a very important element to at least one aspect of its innovation activities. Thus, based on 4-level semantic differential scale, firms that consider a university as "very important" for at least one of the following: (a) suggesting new innovation projects, (b) finishing undergoing innovation projects, (c) research results, (d) prototypes, (e) new techniques and instruments, (f) laboratories were included into final sample. The procedure resulted in 105 firms.

(1) In the present study only manufacturing firms from the low, medium-low, medium-high and high technological intensities according to OECD Isic Rev. 3 typology (OECD, 2011) were analyzed. The reason is that the use of common typology that comprises all analyzed sectors will help to perform complementary analysis related to R\&D investments (2) For one of the manufacturing companies listed in the BR Survey databank the data on size was missing. 
Figure 1. Procedures of sample selection for innovativeness analysis with csQCA

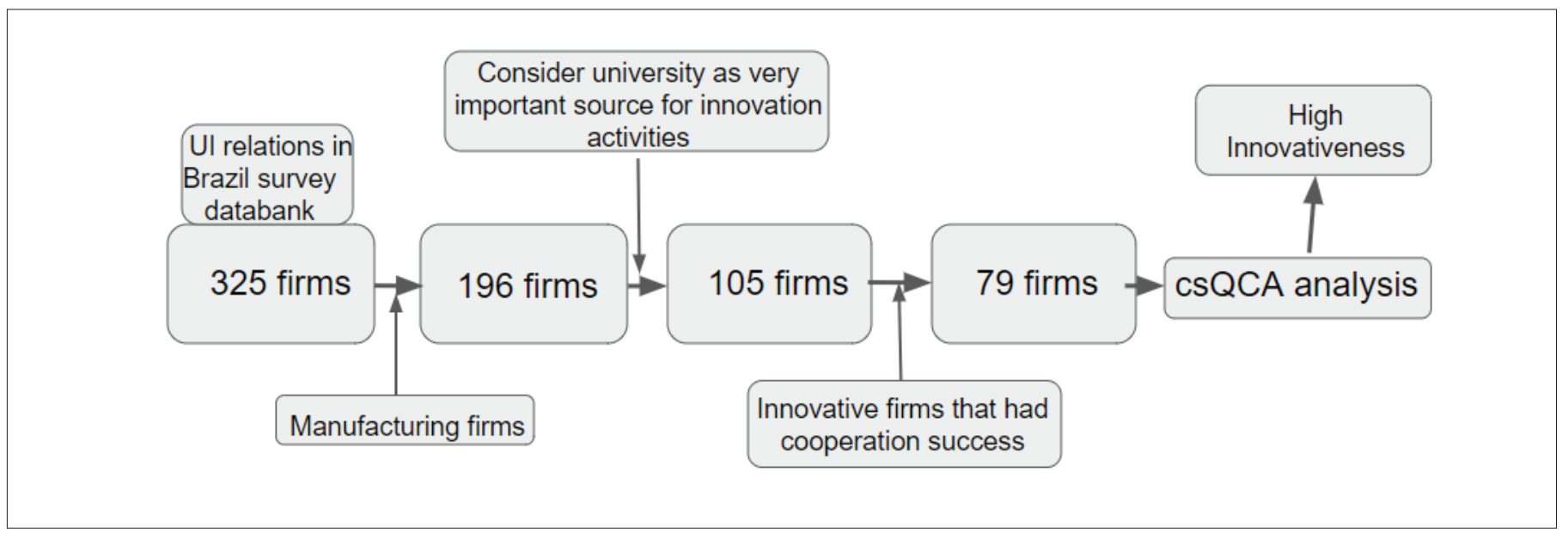

Out of 105 firms, researchers selected only innovative firms that implemented (1) new process or product innovation during the last 3 years and that one that stated that cooperation with the university research succeeded. The procedures resulted in 79 innovative manufacturing firms.

The UI relationships in which 79 remaining firms engaged were mapped through CNPQ Database 2004 and categorized according to Schaeffer's et al. (2017) typology. Previously Schaeffer's et al. (2017) typology had been applied to analyze the UI cooperation from CNPQ Database 2010, therefore, the typology best fit the Brazilian context and available data.

The study employs a crisp-set qualitative-comparative method (using software fsQCA.com) to identify search for UI relations configurations that result in firms' high innovativeness.

The crisp-set qualitative-comparative method (csQCA) was first created by Ragin and uses Boolean Algebra (logic of 1 - present and 0 - absent) to identify the combination, that is, the solution formula of given factors that lead to a specific outcome (Grofman \& Schneider, 2009). The advantage of csQCA over statistical methods such as, for instance, linear regression, is that it allows researchers to suggest what is the combination of factors/conditions that will lead to a given outcome. Likewise, unlike most statistical methods, the csQCA was designed to work with medium-N samples (Ragin, 2014), which is the case of the sample used in the present study $(\mathrm{N}=79)$.

The process of QCA analysis starts with definitions of conditions of the outcome, that is, with the definition of factors that may lead to a given outcome based on the extant theoretical knowledge (Ordanini, Parasuraman, Rubera, 2014). In the present study, we suggest a combinations of 5 types of Schaeffer's et al. (2017) interaction types. Therefore, the study tests the following csQCA model: HInovOut = (TR, SE, DI, DE, RE).

Once created the QCA model, the next step is calibration (Reichert et al., 2016; Rihoux \& Ragin, 2008). In this study, we defined high innovativeness as those innovations that exceed the "novelty to the firm" frontier. Thus, only firms that implemented "new to the country" or "new to the world" product or process innovation in the last 3 years were considered as highly innovative. Concerning the Schaeffer's et al. (2017) interaction types, for each interaction type of each observation it was set 1 when present and 0 when absent.

Crisp-set QCA uses a truth table function to generate configurations of conditions (TR, SE, DI, DE, RE) that are enough for achieving high innovation output (HighInnovOutput). The truth table for all logically possible combinations is 2 elevated on a few conditions (5), that is, 32 rows. To reduce the number of columns, a selection of consistency level is required. Rihoux and Ragin (2008), also Fiss (2011) suggest a consistency cutoff of at least 0.75 . In the present study, it was decided to raise the consistency cutoff to 0.8 .

The output of csQCA includes three types of solution: complex, intermediate, and parsimonious. Ragin (2014) suggests using an intermediate solution, as it represents the balance within complexity and parsimony by using procedures like the practice of conventional caseoriented comparative research. In the present study, however, it was decided to use a parsimonious solution. This solution allows to reduce the number of conditions in each individual solution, as well as, in some cases, the number of individual solutions. In turn, using only parsimonious solutions allows to reduce the total number of analyzed elements when working with more than one frequency cutoff. It's important to add the that together with solution consistency, the "quality" of csQCA solution is measured by solution coverage, which assesses the degree to which solution "accounts for" of an outcome condition, that is, coverage is analogous to R2 in statistical analysis (Ragin, 2014)

After obtaining csQCA solutions, a descriptive analysis of cases covered by the solutions took place.

\section{Results}

The present section is divided into two parts. First, results of csQCA analysis are presented. Then, a descriptive analysis of cases covered by solutions is performed. 


\subsection{CsQCA results}

Table 3 reports the results of the csQCA analysis for high innovation output with frequency cutoff of 1 case.

Table 3. Results of csQCA for high innovation output with frequency cutoff equal to 1 case

\begin{tabular}{l|l|l|l}
\hline Solution configuration & Raw coverage & Unique coverage & Consistency \\
\hline $\mathrm{de}^{*} \mathrm{RE}$ & 0.074074 & 0.055556 & 1.000000 \\
\hline $\mathrm{TR}^{*} \mathrm{se}^{*} \mathrm{RE}$ & 0.055556 & 0.037037 & 1.000000 \\
\hline $\mathrm{SE}^{*} \mathrm{di}^{*} \mathrm{RE}$ & 0.037037 & 0.037037 & 1.000000 \\
\hline $\mathrm{tr}^{*} \mathrm{se}^{*} \mathrm{DE}{ }^{*} \mathrm{re}$ & 0.388889 & 0.388889 & 0.840000 \\
\hline $\mathrm{TR}{ }^{*} \mathrm{SE}{ }^{*} \mathrm{DE}{ }^{*} \mathrm{re}$ & 0.018519 & 0.018519 & 1.000000 \\
\hline solution coverage & 0.555556 & & \\
\hline solution consistency & 0.882553 & & \\
\hline
\end{tabular}

Note: consistency cutoff 0.823528 , frequency cutoff 1.000000

The findings reveal that within analyzed sample there are five configurations of UI relationships that lead to high innovation output (HInovOut): de ${ }^{\star} \mathrm{RE}$ (configuration 1a), $\mathrm{TR}^{\star} \mathrm{se}^{\star} \mathrm{RE}$ (configuration $2 \mathrm{a}$ ), $\mathrm{SE}^{\star} \mathrm{di}^{\star}$ $\mathrm{RE}$ (configuration $3 \mathrm{a}$ ), $\operatorname{tr}^{\star} \mathrm{Se}^{\star} \mathrm{DE}^{\star}$ re (configuration $4 \mathrm{a}$ ) and $\mathrm{TR}^{\star} \mathrm{SE}^{\star} \mathrm{DE}^{\star} \mathrm{re}$ (configuration 5a). Despite low raw coverage of individual solutions, the overall coverage is 0.555556 , which is above 0.4 as the minimum threshold suggested by Rihoux and Ragin (2014). The solution presents good consistency (0.88). The finding indicates that development-oriented interaction and research-oriented interaction are the only interactions that alone can lead the firm to high innovativeness. The training-oriented and service-oriented interactions lead to high innovativeness only in a presence of development-based or research-based interaction. In turn, the diffusion-oriented is absent in all five configurations, which means that it does not contribute to high innovativeness.

Ragin (2014) suggests that the ideal number of cases for csQCA is around 30. Therefore, as the number of cases is 79 , the researchers decided to run the data with frequency cutoff of 2 cases. Table 4 reports the results of the csQCA analysis for high innovation output with frequency cutoff of 2 cases.

Table 4. Results of csQCA for high innovation output with frequency cutoff equal to 2 cases

\begin{tabular}{l|l|l|l}
\hline Solution configuration & Raw coverage & Unique coverage & Consistency \\
\hline $\mathrm{de}^{*} \mathrm{RE}$ & 0.074074 & 0.055556 & 1.000000 \\
\hline $\mathrm{TR}{ }^{*} \mathrm{se}{ }^{*} \mathrm{RE}$ & 0.055556 & 0.037037 & 1.000000 \\
\hline $\mathrm{tr}^{*} \mathrm{se}^{*} \mathrm{DE}{ }^{*} \mathrm{re}$ & 0.388889 & 0.388889 & 0.840000 \\
\hline solution coverage & 0.500000 & & \\
\hline solution consistency & 0.870968 & & \\
\hline
\end{tabular}

Note: consistency cutoff 0.823529 , frequency cutoff 2.000000

As observed in Table 4, the number of configurations of UI relations that lead to high innovation output (HInovOut) reduces to three. They are: $\mathrm{de}^{\star} \mathrm{RE}$ (configuration $1 \mathrm{~b}$ ), $\mathrm{TR}^{\star} \mathrm{se}^{\star} \mathrm{RE}$ (configuration $2 \mathrm{~b}$ ), $\operatorname{tr}^{\star} \mathrm{Se}^{\star} \mathrm{DE}^{\star}$ re (configuration $3 \mathrm{~b}$ ). Again, despite low raw coverage of individual solutions, the overall coverage is 0.50 , which is above 0.4 as the minimum threshold suggested by Ragin (2014). The solution also presents good consistency (0.87). As in the case of QCA model with frequency cutoff 1 , the QCA model with frequency cutoff 2 finding indicates that a single UI interaction type, alone, cannot lead the firm to high innovativeness except for development-oriented interaction and research-oriented interaction. The training-oriented and service-oriented interactions lead to high innovativeness only in a presence of development-based or research-based interaction. In turn, the diffusion-oriented does not appear in all three configurations, which means that it doesn't contribute to high innovativeness.

These results are aligned with the perception of academic scholars that argue high innovation outcomes usually come from more complex, longterm interactions UI interactions focused on knowledge or product creation (Arza, 2010; Mansfield, 1991; Schaeffer et al., 2017). In contrast, interactions based on consultancy and services may not be enough to achieve advanced levels of innovativeness (Arza, 2010; Puffal \& Teixeira, 2014).

(3) Upper case represents types of interactions that must be present and lower case those that must be absent 
The results concerning a diffusion-oriented interaction are quite interesting also. Schaeffer et al. (2017) define it as "public technological knowledge and currently available solutions, without a high level of complexity". Thus, it is possible to suppose as these sources are accessed by the firms that are publicly available, they do not lead to superior innovative performance. This supposition is in line with the resource-based view (Barney, 1996). In contrast, service-oriented and training-oriented interactions, despite low complexity, still may be subjected to personalization to some extent.

Likewise, it is important to stress that, once the firm achieved high innovation despite having invested relatively low amounts of capital in internal $\mathrm{R} \& \mathrm{D}$, it is because of the ties with research groups that it was able to achieve such a high level of innovation. The present findings are in line with Schaeffer et al. (2017) perception, who argued that development-oriented and research-oriented relations are the most desirable for the firms to engage with in order to access valuable knowledge that in turn will increase the ability of the firm to innovate. Thus, based on the solutions presented. A possible explanation for that could be the high level of absorptive capacity and knowledge exchange required to perform these relationships (Schaeffer et al., 2017). In turn, contact with scientific and technological knowledge of universities seems to be one of the influential factors on firm high innovativeness (Murovec \& Prondan, 2009).

\subsection{Analysis of successful cases}

The present subsection includes analysis of successful cases covered by QCA solution presented at Table 3, that is, those that had one of the following UI interactions configurations: $\mathrm{de}^{\star} \mathrm{RE}$ (configuration 1a), $\mathrm{TR}^{\star} \mathrm{Se}^{\star} \mathrm{RE}$ (configuration 2a), $\mathrm{SE}^{\star} \mathrm{di}^{\star} \mathrm{RE}$ (configuration $3 \mathrm{a}$ ), $\operatorname{tr}^{\star} \mathrm{Se}^{\star} \mathrm{DE}^{\star} \mathrm{re}$ (configuration $4 \mathrm{a}$ ) and $\mathrm{TR}^{\star} \mathrm{SE}^{\star} \mathrm{DE}^{\star}$ re (configuration $5 \mathrm{a}$ ). The decision to present cases covered by a solution with a frequency cutoff of 1 case was made due to presenting higher coverage than the solution with frequency cutoff 2, allowing analysis of a larger number of successful cases. As shown in Table 5, the cases covered by csQCA solutions are diverse in terms firm's size and R\&D intensities and economic sectors.

Therefore, it is possible to suppose that once the firm cooperates with the universities based on UI relations configurations shown in Table 3 and Table 4, it will have high innovation output regardless of the firm's size, sector, or R\&D intensity.

From Table 5 it is also possible to infer that, in general, companies from BR survey, that are highly innovative, have a relatively low investment in $\mathrm{R} \& \mathrm{D}$. The R\&D investment is relatively low even in sectors that, according to OECD (2011) should have high or medium-high technological intensity. For instance, according to OECD (2011) sectors that invest up to $1 \%$ of revenue in R\&D are considered low technological intensity and those that invest between $1 \%$ and $2,5 \%$ of revenue in R\&D activities as of medium-low technological intensity. However, 13 out of 28 companies listed at Table 5 invest no more than $3 \%$ of revenue in $\mathrm{R} \& \mathrm{D}$, including companies from the pharmaceutical sector (2), chemical sector (2), machinery, and equipment (1).

To determine if the cases covered by csQCA solution are statistically different from other firms from the overall sample of 196 manufacturing firms, a $T$ test was carried out. Table 6 shows that there are no statistically significant differences at $\mathrm{p}<0,05$ between the two samples in terms of R\&D intensity. Therefore, we again argue that it is not due to R\&D intensity that firms from cases covered by csQCA solutions are highly innovative but due to undertaken configurations of UI interaction. Our position is reinforced by the fact that all firms from the analyzed sample stated that UI interaction is an important factor for their innovation activities.

Table 5. Economic sectors, size and R\&D intensity of manufacturing firms covered by csQCA solution

\begin{tabular}{|c|c|c|c|c|c|c|c|}
\hline Sector & \multicolumn{3}{|l|}{ Size } & \multicolumn{4}{|c|}{$R \& D$ investment (\% of revenue) } \\
\hline Automobile & 0 & 0 & 1 & 0 & 1 & 0 & 1 \\
\hline Chemical products & 0 & 4 & 3 & 1 & 1 & 5 & 7 \\
\hline Communication equipment & 0 & 1 & 0 & 0 & 0 & 1 & 1 \\
\hline Food and beverage & 0 & 1 & 1 & 0 & 2 & 1 & 2 \\
\hline Machinery and equipment & 0 & 1 & 1 & 0 & 1 & 1 & 2 \\
\hline Metal products & 1 & 2 & 2 & 1 & 3 & 1 & 5 \\
\hline Oil and fuel & 0 & 0 & 1 & 0 & 0 & 1 & 1 \\
\hline Total & 3 & 12 & 13 & 3 & 10 & 15 & 28 \\
\hline
\end{tabular}

Note. Source: elaborated by the authors 
Table 6.T test for R\&D intensity mean differences

\begin{tabular}{|c|c|c|c|c|c|}
\hline Cases & $\mathbf{N}$ & Mean & St. Deviation & T test & Sig. (2-tailed) \\
\hline Covered by csQCA solution & 167 & 2.29 & 1.1564 & \multirow{2}{*}{-1.823} & \multirow{2}{*}{0.070} \\
\hline Other manufacturing firms & 29 & 2.72 & 1.1830 & & \\
\hline
\end{tabular}

Note. Source: elaborated by the authors

\section{Conclusion}

The csQCA analysis showed that development-oriented interaction and research-oriented interaction, which are the most complex UI interactions (Schaeffer et al., 2017) are the only UI interactions that alone lead the firm to high innovativeness. In contrast, service-oriented and training-oriented relations, which usually comprise low levels of complexity (Schaeffer et al., 2017), lead the firm to innovate beyond "new-to-the-firm" borders only when complemented by development-oriented or research-oriented interactions. Diffusion-oriented interaction, which also presents a lower level of complexity than development-oriented and research-oriented interactions, showed no contribution to high innovativeness, as it does not appear in any of the solution's configurations.

The study also revealed that highly innovative firms covered by csQCA solutions have relatively low R\&D investment rates, even when they are from high and medium-high technological intensity sectors according to OECD's (2011) Isic 3 classification. This finding allows us to infer that firms that are engaged in development-oriented interaction or research-oriented interaction with universities can effectively achieve high innovativeness even in the absence of high R\&D investments. These finding stresses, even more, the importance of engaging in complex and long-term interactions with universities for the firms that want to become highly innovative.

The present study contributes to the literature in three ways. First, this is the first study to apply crisp-set QCA to identify configurations of UI interactions that lead to the firm's high innovativeness. Second, unlike previous investigations, our study determines which are the necessary conditions that allow firms engaged in UI interaction to achieve high innovativeness and which are not. In addition, the method applied, and the findings of the present paper empirically validate the Schaeffer's et al. (2017) UI interaction typology. It is important to highlight that, unlike many previous studies, the present article analyzes the sample composed exclusively by firms that consider university as an important agent to its innovative activities and has cooperation success. In turn, this sample composition enhances the qualitative validity of the used factors and outcomes.

We expect that the results will help managers to better formulate strategies of engaging in UI interactions and to choose a suitable configuration of UI interaction for the results they want to achieve. Finally, the finding of the present study may motivate the government and policymakers to formulate strategies that promote policies that aim to engage the firms and universities into more complex and long-term interactions.
The study has some limitations. First, the present study uses data from the first decade of the century and therefore it would be important to perform the same study with more recent data. Second, the present study measures the firm's innovativeness through one variable, which is also the only output variable available in the BR survey database and therefore it is important to incorporate other innovativeness measures in further investigations.

For future studies, it would be interesting to expand the present research to sectors beyond manufacturing firms. The replication of the study in the context of advanced innovative economies seems to be an interesting opportunity also.

It should be noted that due to this being the first study on the results of university-industry interaction which applies the csQCA, it is likely that there are possibilities for improvement in the adjustments made in the csQCA configuration.

\section{Acknowledgments}

This study was partially financed by the Coordenação de Aperfeiçoamento de Pessoal de Nível Superior - Brazil (CAPES) - Finance code 001.

\section{References}

Alexander, A., Martin, D. P., Manolchev, C., \& Miller, K. (2018). University-industry collaboration: using meta-rules to overcome barriers to knowledge transfer. The Journal of Technology Transfer, 1-22.

Andersson, S., \& Berggren, E. (2016). Born global or local? Factors influencing the internationalization of university spin-offs-the case of Halmstad University. Journal of International Entrepreneurship, 14(3), 296-322.

Arant, W., Fornahl, D., Grashof, N., Hesse, K., \& Söllner, C. (2019). University-industry collaborations-The key to radical innovations? Review of Regional Research, 39(2), 119-141.

Arza, V. (2010). Channels, benefits and risks of public-private interactions for knowledge transfer: conceptual framework inspired by Latin America. Science and Public Policy, 37(7), 473-484.

Baba, Y., Shichijo, N., \& Sedita, S. R. (2009). How do collaborations with universities affect firms' innovative performance? The role of "Pasteur scientists" in the advanced materials field. Research Policy, 38(5), 756-764.

Barney, J. B. (1996). The resource-based theory of the firm. Organization science, 7(5), 469-469. 
Bishop, K., D’Este, P., \& Neely, A. (2011). Gaining from interactions with universities: Multiple methods for nurturing absorptive capacity. Research Policy, 40(1), 30-40.

Bonaccorsi, A., \& Piccaluga, A. (1994). A theoretical framework for the evaluation of university-industry relationships. R\&D Management, 24(3), 229-247.

Cohen, W. M., Nelson, R. R., \& Walsh, J. P. (2002). Links and impacts: the influence of public research on industrial R\&D. Management Science, 48(1), 1-23.

Clark, B. (2005). The character of the entrepreneurial university. International Higher Education, (38).

D'este, P., \& Perkmann, M. (2011). Why do academics engage with industry? The entrepreneurial university and individual motivations. The Journal of Technology Transfer, 36(3), 316-339.

D'Este, P., \& Patel, P. (2007). University-industry linkages in the UK: What are the factors underlying the variety of interactions with industry? Research Policy, 36(9), 1295-1313.

Elia, G., Secundo, G., \& Passiante, G. (2017). Pathways towards the entrepreneurial university for creating entrepreneurial engineers: an Italian case. International Journal of Entrepreneurship and Innovation Management, 21(1-2), 27-48.

Etzkowitz, H. (2019). Is Silicon Valley a global model or unique anomaly? Industry and Higher Education, 33(2), 83-95.

Etzkowitz, H., \& Zhou, C. (2018). Innovation incommensurability and the science park. R\&D Management, 48(1), 73-87.

Etzkowitz, H. (1998). The norms of entrepreneurial science: cognitive effects of the new university-industry linkages. Research Policy, 27(8), 823-833.

Fiss, P. C. (2011). Building better causal theories: A fuzzy set approach to typologies in organization research. Academy of management journal, 54(2), 393-420.

Fischer, B. B., Schaeffer, P. R., Vonortas, N. S., \& Queiroz, S. (2018). Quality comes first: university-industry collaboration as a source of academic entrepreneurship in a developing country. The Journal of Technology Transfer, 43(2), 263-284.

Grofman, B., \& Schneider, C. Q. (2009). An introduction to crisp set QCA, with a comparison to binary logistic regression. Political Research Quarterly, 62(4), 662-672.

Henton, D., \& Held, K. (2013). The dynamics of Silicon Valley: Creative destruction and the evolution of the innovation habitat. Social Science Information, 52(4), 539-557.

IBGE, PINTEC Pesquisa de Inovação 2017. IBGE, Rio de Janeiro, 2020. Available at: https://biblioteca.ibge.gov.br/index.php/biblioteca-catalogo?view=detalhes\&id=2101706, accessed on May 7, 2020.
Klevorick, A. K., Levin, R. C., Nelson, R. R., \& Winter, S. G. (1995). On the sources and significance of interindustry differences in technological opportunities. Research Policy, 24(2), 185-205.

Kobarg, S., Stumpf-Wollersheim, J., \& Welpe, I. M. (2018). University-industry collaborations and product innovation performance: The moderating effects of absorptive capacity and innovation competencies. The Journal of Technology Transfer, 43(6), 16961724.

Lam, A. (2007). Knowledge networks and careers: Academic scientists in industry-university links. Journal of Management Studies, 44(6), 993-1016.

Li, X., Li, J., \& Wu, X. (2020). University spillovers, spatial distance, and firm innovation: Evidence at Chinese listed firms. Emerging Markets Finance and Trade, 56(7), 1504-1519.

Mansfield, E. (1991). Academic research and industrial innovation. Research Policy, 20(1), 1-12.

Mascarenhas, C., Ferreira, J. J., \& Marques, C. (2018). University-industry cooperation: A systematic literature review and research agenda. Science and Public Policy, 45(5), 708-718.

Mazzoleni, R., \& Nelson, R. R. (2007). Public research institutions and economic catch-up. Research Policy, 36(10), 1512-1528.

Meyer-Krahmer, F., \& Schmoch, U. (1998). Science-based technologies: university-industry interactions in four fields. Research Policy, 27(8), 835-851

Miller, K., Alexander, A. T., Cunningham, J., \& Albats, E. (2018). Entrepreneurial academics and academic entrepreneurs: A systematic literature review. International Journal of Techology Management, 77(1, 2, 3), 9-37.

Murovec, N., \& Prodan, I. (2009). Absorptive capacity, its determinants, and influence on innovation output: Cross-cultural validation of the structural model. Technovation, 29(12), 859-872.

Nelson, R. R. (1990). Capitalism as an engine of progress. Research Policy, 19(3), 193-214.

Organization for Economic Cooperation and Development OECD (2011). Technology intensity definition. ISIC rev.3. Available at: https://www.oecd.org/sti/ind/48350231.pdf. Accessed at: 3rd January 2020

Pinho, M. (2018). Mais do que se supõe, menos do que se precisa: relações entre universidades e empresas no Brasil. In: Garcia, R., Rapini, M., Cario, S. Estudos de caso da interação universidade-empresa no Brasil, Belo Horizonte, FACE/UFMG, 35-57.

Puffal, D. \& Teixeira, R. (2014). Effects of university-industry interaction on firm's innovation: Empirical evidence from Brazilian firms. Revista Ibero-Americana de Estratégia-RIAE, 13(1), 7-21 
Puffal, D. P., Ruffoni, J., \& Schaeffer, P. R. (2012). Características da interação universidade-empresa no Brasil: motivações e resultados sob a ótica dos envolvidos. Gestão Contemporânea, (1), 71-94

Ragin, C. C. (2014). The Comparative Method: Moving Beyond Qualitative and Quantitative Strategies. Univ of California Press.

Reichert, F. M., Zawislak, P. A., \& Arundel, A. (2016). Exploring innovation success recipes in low-technology firms using fuzzy-set QCA. Journal of Business Research, 69(11), 5437-5441.

Rihoux, B., \& Ragin, C. C. (2008). Configurational comparative methods: Qualitative comparative analysis (QCA) and related techniques (Vol. 51). Sage Publications.

Rosenberg, N., \& Nelson, R. R. (1994). American universities and technical advance in industry. Research Policy, 23(3), 323-348.

Santoro, M. D. (2000). Success breeds success: The linkage between relationship intensity and tangible outcomes in industry-university collaborative ventures. The Journal of High Technology Management Research, 11(2), 255-273.

Schaeffer, P. R., Dullius, A. C., Rodrigues, R. M., \& Zawislak, P. A. (2017). Searching to bridge the gaps: a new typology of universityindustry interaction. Academia Revista Latinoamericana de Administración, 30 (4), 459-473.
Shi, X., Wu, Y., \& Fu, D. (2020). Does University-Industry collaboration improve innovation efficiency? Evidence from Chinese Firms $\diamond$. Economic Modelling, 86, 39-53.

Skute, I., Zalewska-Kurek, K., Hatak, I., \& de Weerd-Nederhof, P. (2019). Mapping the field: a bibliometric analysis of the literature on university-industry collaborations. The Journal of Technology Transfer, 44(3), 916-947.

Smith, K. Measuring Innovation. In: Fagerberg, J; Mowery, D.; Nelson, R. The Oxford Handbook of Innovation. Estados Unidos: Oxford, 2004, p.149-177

Trencher, G., Bai, X., Evans, J., McCormick, K., \& Yarime, M. (2014). University partnerships for co-designing and co-producing urban sustainability. Global Environmental Change, 28, 153-165.

Wang, Y., Hu, D., Li, W., Li, Y., \& Li, Q. (2015). Collaboration strategies and effects on university research: evidence from Chinese universities. Scientometrics, 103(2), 725-749.

Yoon, J. (2015). The evolution of South Korea's innovation system: moving towards the triple helix model? Scientometrics, 104(1), 265293. 
